\title{
O FAZER DA ENFERMEIRA NO SISTEMA LOCAL DE SAÚDE: INDIVIDUAL OU COLETIVO?
}

THE NURSE'S DOING IN HEALTH LOCAL SYSTEM: INDINIDUAL OR COLLECTIVE?

\section{Marluce Maria Araújo Assis ${ }^{1}$}

\begin{abstract}
RESUMO: Este ensaio consiste em uma reflexão teórica acerca do fazer da enfermeira no Sistema Local de Saúde (SILOS), permitindo compreender (ainda que provisoriamente) se o espaço que vem sendo ocupado pela mesma, na "porta de entrada" dos serviços de saúde, tem possibilitado uma construção ideológica de sua ação social, enquanto sujeito coletivo ou individual. Assim, procuramos nos pautar teoricamente no pensamento de Testa (1995) e apontamos o SILOS, enquanto um espaço social de transformação do Sistema de Saúde. Discutimos também, as relações vivenciadas no cotidiano da organização institucional, tentando entender o processo de produção de sujeitos sociais, focalizando a enfermeira nesta construção.
\end{abstract}

UNITERMOS: Sistema local de saúde - Ator individual e coletivo - Práticas de saúde.

\section{INTRODUÇÃO}

A concepção de Sistema Local de Saúde (SILOS) traz embutida a idéia de descentralização, entendida como um instrumento de reestruturação do poder, na dimensão política, técnica e administrativa da organização dos serviços de saúde. Essa reestruturação tem como eixo principal a inversão da relação do nível central (federal) e intermediário (estadual) com o nível local (município) na formulação e implementação de políticas, organização e gestão dos processos de trabalho e a utilização e manejo de recursos humanos, físicos e materiais.

Nesse sentido, a busca de construção de um processo descentralizador nas duas últimas décadas tem como finalidade exercer uma maior eficiência administrativa e um maior impacto epidemiológico sobre os problemas de saúde existentes na população brasileira. Tais pressupostos foram pontos de convergência entre instituições brasileiras e organismos internacionais a exemplo da Cooperação Italiana e Organização Panamericana de Saúde (OPS).

Algumas experiências localizadas em São Paulo, Salvador e Rio de Janeiro apontam que essas estratégias de reorganização do sistema de saúde são parte de um processo mais global de reorganização do setor saúde na América do Sul

${ }^{1}$ Enfermeira, docente da Universidade Estadual de Feira de Santana - Ba, Doutoranda do Programa Interunidades da Escola de Enfermagem de Ribeirão Preto da Universidade de São Paulo. 
e que, embora vivenciem situações distintas (tanto internamente quanto externamente), do ponto de vista político institucional, assemelham-se em relação às condições de vida da maioria da população. (Teixeira \& Melo (Org.), 1995), (Kadt \& Tasca, 1993), (Bodstein (Org.),1993).

Como conseqüência, surge a necessidade de constituir equipes com um novo instrumental técnico específico para análise, avaliação e controle desses sistemas.

Esta necessidade social tem possibilitado uma construção e reconstrução, por aproximações sucessivas, da definição de um modelo gerencial local, intermediado pelas Secretarias Municipais de Saúde, tendo como um dos principais atores desse processo, a enfermeira que atua na rede de atendimento primário, tendo como "locus" de ação as Unidades Básicas de Saúde.

A expressão atores, epistemologicamente, pode ser compreendida em duas categorias: atores individuais e coletivos, constituídos por uma ou múltiplas pessoas, muito bem explicitada por Testa (1995:49)

\footnotetext{
" Ulm ator individual é um sujeito que tem interesses no setor saide eque ocupa uma pasição que a coloca em situaçãa de peso dentro do mesmo. Surge a interrogação se existe uma identidade entre o conceito de ator $e 0$ sujeito ator."
}

Por outro lado, o nosso entendimento do fazer da enfermeira não é isolado do trabalho em saúde, pelo contrário, é parte deste, o qual denominamos de trabalhador coletivo. Esta abordagem foi muito bem estudada por Almeida (1991) ao analisar: "O Trabalho de Enfermagem e sua Articulação com o Processo de Trabalho em Saúde Coletiva - Rede Básica de Saúde em Ribeirão Preto.

Este fazer, no entanto, não pode estar desarticulado do movimento de descentralização da saúde em nível local, operacionalizado através da divisão dos municípios em Distritos Sanitários².

Este espaço social tem se configurado num campo de luta, político-ideológico e técnico, de definição de práticas e alternativas de mudança do atual modelo assistencial de saúde.

2 Entendido como um processo social de mudanças das práticas sanitárias, diferente da chamada concepção "topográfica-burocrática". Conforme enfatiza MENDES (1994:159), ao colocar uma série de problemas e desafios teóricos práticos na operacionalização de Distritos Sanitários: "a necessidade de se desenvolverem experiências que apontem os problemas metodológicos e organizativos do processo e que, ao serem objeto de reflexão e sistematização teórica, permitam que se avance com proposições práticas em uma espiral contínua de açãoreflexão-ação". 
O pensamento de Testa(1995) permite compreender se o espaço que vem sendo ocupado pela enfermeira na "porta de entrada" dos serviços de saúde tem possibilitado uma construção ideológica de sua ação social. Considerando que o sujeito social é coletivo e não individual, necessitando de uma capacidade organizativa para se buscar algo e que todo poder está contido em uma forma organizativa, a nossa questão é a seguinte: A enfermeira é um sujeito individual ou social neste espaço institucional?

O objetivo do presente ensaio, é refletir sobre a prática da enfermeira (e o seu processo de constituição, enquanto ator social), bem como as práticas sanitárias desenvolvidas no espaço institucional/social dos serviços locais de saúde.

Tomamos como ponto de partida o postulado teórico da Reforma Sanitária que aponta como caminho a redefinição de um novo agir em saúde através da formulação e operacionalização de políticas, onde novos atores aparecem e identidades coletivas são construídas.

\section{O SISTEMA LOCAL DE SAÚDE: UM ESPAÇO SOCIAL DE TRANSFORMAÇÃO DO SISTEMA DE SAÚDE}

A busca de melhor efetividade no atendimento à saúde tem produzido e estimulado transformações no setor saúde brasileiro, principalmente a partir da década de oitenta. Diversas iniciativas vêm sendo empregadas, considerando aspectos demográficos e perfís epidemiológicos de populações específicas.

Internacionalmente, a proposta SILOS apresenta-se como "a coluna vertebral da atenção primária de saúde" (Tarimo, E.; Fowkes, F.G. R., 1989), traduzindose na organização dos serviços de saúde de nosso país, a dinâmica desta evolução, centrada na consolidação de processos institucionais e na expansão de cobertura assistencial inaugurados em fins da década setenta.

Amplia-se o debate sobre os cuidados primários de saúde, regionalização e hierarquização dos serviços. Os projetos SILOS buscam, em torno da estrutura de ofertas das unidades de saúde de complexidade distinta, adequar a oferta a necessidades de saúde das diferentes comunidades.

Assim, esta estratégia passa a ser discutida, tendo como fórum político importante a VIII Conferência Nacional de Saúde em $1986^{15}$, com participação de 4000 pessoas, que representaram os usuários, os prestadores de serviço, os trabalhadores e os dirigentes de saúde, assim como as várias representações políticas nacionais.

A noção de SILOS é amplamente difundida e iniciou-se como movimento de viabilização prática, via propostas "racionalizadoras e reformistas", através das Ações Integradas de Saúde (AIS), Sistema Unificado e Descentralizado de Saúde (SUDS) e Sistema Único de Saúde (SUS), particulamente apoiadas pelas diretrizes de Municipalização e Descentralização. 
No plano operacional, o Distrito Sanitário (e as Unidades de Saúde de sua área de abrangência) é o espaço institucional definido para a viabilização de um Sistema que possa garantir os preceitos Constitucionais assegurados na Carta Magna brasileira de 1988, obedecendo aos seguintes princípios norteadores:

Universalização - que confira igualdade de direitos a qualquer cidadão brasileiro, sem que haja distinção no atendimento à saúde entre os serviços federal, estadual ou municipal, pois todos seriam parte de um Sistema Único de Saúde.

Eqüidade - a garantia de acesso por necessidades iguais enquanto valor e princípio normativo de estruturação dos serviços de saúde, ou seja, não permitiria distinções entre um brasileiro e outro, no valor de sua vida. Todos sendo considerados como um patrimônio da sociedade.

Integralidade dos cuidados assistenciais;

Regionalização e Integração dos serviços de saúde;

Descentralização - financeira, de poder e de autonomia relativa aos municípios para melhoria da eficiência e eficácia dos serviços ao nível local;

Participação e Controle Social - enquanto instâncias problematizadoras, de exercício da democracia e da atualização de identidade das lutas de saúde no pais.

Tais diretrizes objetivaram reunir, unificar o que está disperso, paralelo e desordenado. Significa a possibilidade de um sistema unificado caracterizado pela pluralidade de sistemas adaptados às respectivas realidades locais, mas possuindo, todos eles, pontos comuns de agregação que permitam a sua articulação em um sistema maior.

Esses pontos convergentes seriam as características básicas do sistema, quais sejam: a descentralização, a gestão colegiada e participativa, a integração de recursos e o desenvolvimento de uma política de recursos humanos com capacitação técnica e gerencial, como um intercâmbio de relações e não como uma ação isolada de um único agente.

Ressaltamos que estas proposições encontram-se ainda no "ideário discursivo", com algumas experiências pontuais, traduzindo-se na prática com políticas focalizadoras direcionadas a populações pobres, seletivamente escolhidas pela sua maior necessidade e urgência.

Draibe (1993) assinala que as políticas sociais preconizadas pelo neoliberalismo tem confirmado mudanças nos modos de produzir e distribuir os bens e serviços sociais, numa lógica privada, com mecanismos ágeis e eficientes em atender as demandas aptas a se inserirem em alguma forma privada de produção dos serviços de saúde.

A descentralização, na concepção neoliberal, é concebida para aumentar as possibilidades de "interação", no nível local, como um modo de aumentar a eficiência e a eficácia do gasto dos recursos públicos e não governamentais, para o financiamento das atividades sociais. 
Em trabalho produzido anteriormente (Assis,1994), afirmávamos que a Municipalização só representa avanço como um processo descentralizador se vier acompanhada de articulação com outras esferas de poder (público e privado), sob regulação do Estado e o estabelecimento de mecanismos que propiciem um espaço de construção democrática, na definição de relações dos diferentes níveis de poder existentes no micro espaço territorial do município, através da participação dos trabalhadores de saúde e do sujeito/cidadão de forma organizada, nas instâncias deliberativas do processo de gestão local.

Dessa forma, reconhecemos que o SILOS ainda é uma possibilidade de gestão local compartilhada, expressando um movimento contra-hegemônico de determinações histórico-sociais que, para tornar-se real, exige o estabelecimento de "um bloco histórico consensual", na defesa de um projeto de transformação social, enquanto um "determinado grupo, precisamente o de todos os elementos sociais que partilham um mesmo modo de pensar e agir" (Gramsci, 1991).

Por outro lado, a ideologia dominante criou um tipo de universalização, o "universalismo excludente", (Mendes, 1994), contribuindo para inibir as bases sociais da Reforma Sanitária quando incorpora grupos das camadas médias da' população, através do subsistema privado (medicina de grupo, seguro saúde, cooperativas médicas e outros) e a força de mobilização dos sindicatos ligados aos setores industriais modernos.

Convém lembrar que o sistema de saúde brasileiro é composto por três subsistemas: o subsistema de alta tecnologia, o subsistema de atenção médica supletiva e o subsistema público, segundo o autor acima citado.

O subsistema de atenção médica supletiva é o que detém a hegemonia, beneficiando-se do "universalismo excludente", cobrindo $22 \%$ de pessoas que adoecem, pois tem como objeto a doença e suas seqüelas incapacitantes.

O subsistema público atende $75 \%$ da população, o que representa uma ampla estrutura de serviços (hospitais, laboratórios, ambulatórios especializados, postos e centros de saúde...). Este subsistema compõe-se dos serviços estatais, diretamente pela União, Estados e Municípios, e dos privados que, de alguma forma, são pactuados com o Estado, recebendo recursos públicos pela prestação dos serviços.

As experiências de práticas alternativas em saúde, com gestão colegiada, enfatizando princípios organizativos sanitários, segundo a singularidade de cada local específico, têm sido possível em alguns cantos do país, pela vontade de alguns políticos progressistas que dirigem a saúde na esfera municipal; articulados com trabalhadores e população organizada, que em determinados momentos ocupam o poder, e por intelectuais defensores do ideário reformista.

Dentre os autores que produziram, explicitando experiências concretas, citamos: (Bodstein (Org.), 1993), (Kadt \& Tasca, 1993), (Teixeira \& Melo (Org.), 1995). 
O trabalho de Bodstein (Org.) (1993) é voltado para a extensão de cobertura em serviços de saúde da Baixada Fluminense e a Região de Leopoldina no Rio de Janeiro.

Nestas duas realidades, os autores discutem o dilema do processo participativo, num espaço institucional criado pelo setor público. O estudo aborda a questão do acesso da população aos diversos níveis de atendimento e os mecanismos que a própria pópulação cria para usar o serviço. Compara os princípios reformistas, pautados na concepção de saúde integral, com o concreto das unidades de saúde, concluindo que: o acesso real não ocorre em função de uma hierarquização formal idealizada, mas, pelo contrário, da utilização de diversas estratégias que a população utiliza, em face dos constrangimentos impostos pela precariedade da oferta, mostrando-se ineficiente e incapaz de atender o quadro epidemiológico dos grandes centros urbanos.

As experiências de Salvador e São Paulo contaram com contribuições da Cooperação Italiana - financeira e técnica - inseridas num projeto mais global da OPS/OMS (Organização Mundial de Saúde), com a finalidade de atingir a eqüidade, para os "menos privilegiados", ressaltando estratégias como a reorganização, a descentralização e a intersetorialidade dos serviços de saúde.(Kadt \& Tasca, 1993); (Teixeira \& Melo, Org., 1995).

Nesse contexto, o processo social de mudança das práticas de saúde, referido pela estratégia da Reforma Sanitária brasileira - situado no SILOS, exige uma organização do trabalho pautado na epidemiologia ${ }^{3}$, ainda que não negue a importância do saber clínico.

Entender o SILOS como um espaço social de transformação significa a possibilidade de edificação de um novo paradigma que valorize a vida e não a doença, apontando para uma nova lógica integrando o homem no seu habitat social, sem perder de vista os seus valores, crenças, culturas e suas manifestações mais íntimas no plano subjetivo. É nesta direção que pretendo situar a enfermeira, enquanto sujeito individual/coletivo deste processo de construção social.

\section{A ENFERMEIRA: ATOR (INDIVIDUAL OU SOCIAL?) NO COTIDIANO INSTITUCIONAL}

O ator é socialmente construído ou "fabricado" (Castoriadis, 1992), como um produto de transformação pautado na "linguagem e na família", transformação esta que, a partir da "soma-psique singular", produz a essência organizativa dos indivíduos, definindo e orientando no seu papel profissional, nas suas motivações, nas suas idéias e seus valores.

3 Como ciência e como recurso técnico que tem a dimensão prática como mediadora principal, entre si e as condições gerais da sociedade, que coloca os esforços na transformação das condições de vida de grupos de populações e na modificação de sua condição geral de saúde. 
Ao tomar a enfermeira como um sujeito humano na dimensão do indivíduo social significa ir além de uma profissão com sua competência técnico-científica e entendê-la como uma prática social.

Almeida (1991) analisa o trabalho de enfermagem no Sistema Local de Saúde de Ribeirão Preto, em três Unidades Básicas de Saúde, optando por um referencial teórico-metodológico que explica a enfermagem enquanto trabalho uma prática social e historicamente determinada. Com esta abordagem, a autora identifica que: o modelo predominante é o Pronto Atendimento em Saúde; as atividades estão diretamente relacionadas para a consulta médica, centrada nas queixas dos clientes, e afirma: "...as atividades de enfermagem voltam-se também para esta ação; são portanto atividades auxiliares da consulta médica" (p.253).

Partindo do princípio de que este modelo de assistência médica, pautado na queixa-conduta, passa por uma grave crise de eficácia e, principalmente, de prevenir $\odot$ agravamento de situações de risco para a saúde de indivíduos ou da coletividade, é que defendemos, uma verdadeira reforma no modo de fazer "atendimento à saúde". Ou seja, os serviços de saúde teriam que ser estruturados oferecendo atividades amplas, como atenção domiciliar, trabalhos de grupos, palestras, debates, orientações educativas e individuais, e não somente consultas médicas e odontológicas de urgência ou programadas.

Esta nossa proposição certamente foi muito influenciada pelas leituras de autores, como (Campos 1991, 1992a, 1992b) e Merhy (1992), que acreditam e defendem um modelo de saúde em defesa da vida, através da gestão democrática, saúde como direito de cidadania e serviço público de saúde voltado para a defesa da vida individual e coletiva.

Nesta perspectiva, a ampliação das atividades só se justifica com a obrigatoriedade de equipes de saúde pública (médicos generalistas e especializados, enfermeiras, e outros profissionais de saúde) no sistema local, que se responsabilizem pela implementação de forma sistemática e planejada da vigilância em saúde - epidemiológica e sanitária -, desenvolvendo ações de: planejamento, proçedendo à elaboração de diagnósticos de morbi-mortalidade; avaliação da eficácia dos serviços e dos graus de riscos dos vários agrupamentos sociais; dirigir e coordenar ações específicas voltadas para 0 controle e erradicação de doenças de massa e dar apoio a todos que trabalhem o tema da formação de uma nova consciência sanitária entre os trabalhadores de saúde e a.população.

A partir destas colocações temos clareza que as proposições referenciadas são "imagens-objetivos", no processo de constituição de atores sociais capazes de alterar o quadro atual institucional, viabilizando transformações concretas no Sistema Público de Saúde. Até mesmo porque as questões ligadas à prática cotidiana nos serviços de saúde ligam-se à totalidade da existência humana. São portanto, históricas, sociais e culturais. 
E importa notar, como cita Foucault (1986), que a inserção da medicina na "ciência", como um saber dominante, se deu através de sua socialização, enquanto coletiva, social e urbana, e passa da análise do meio e dos efeitos do meio para análise do próprio organismo. A natureza passível de ser observada, mensurada, organizada, classificada, torna-se objeto de controle humano e desenvolvem e consolidam as ciências naturais. Entre elas, a biologia, anatomia, fisiologia, sustentam novos saberes a respeito destes corpos orgânicos. A prática médica fundamenta-se nestes padrões de saberes, institucionalizando-se como hegemônica e, em conseqüência, a agregação de outras áreas de atuação e saber complementares já no século XIX, e no caso em foco a enfermagem (e a enfermeira).

A abordagem trazida por Testa (1995) sobre a conformação dos atores sociais, toma como base a socialização que se dá na dependência de processos formativos, onde se realizam as instâncias familiares e educativas e na dinâmica social, econômica e global. Neste movimento intercomplementar, as relações do científico com o político são evidenciadas a partir da constituição do sujeito coletivo e a transformação em ator social individual.

$\mathrm{O}$ ator individual se constitui em sujeito social, através da "capacidade e relação social", significa que todo poder está contido em uma forma organizativa, se adequando ou resistindo ao objeto de trabalho. $\dot{E}$ na contradição (diferença que se manifesta em forma de discurso) e no conflito (se dá ao nível da ação) que instalamos novos espaços de luta e defendemos um projeto de transformação. O sujeito social só pode ser construido coletivamente e constituído na organização.

A partir desta perspectiva analítica, consideramos que a enfermeira ainda não se constituiu em sujeito social, pois tem acompanhado e não incorporado este processo social de mudanças das práticas sanitárias.

A sua representação tem se dado enquanto sujeito individual, inserida em instituições públicas e/ou privadas. O sujeito social é a instituição e não a enfermeira. Instituição esta que tem adotado ao longo do tempo uma prática baseada no saber clínico (médico), ficando a sensação de que o modelo SILOS, como espaço de mobilização e de inserção social de práticas alternativas e como conseqüência de articulação entre enfermeiras para edificação de uma nova prática, não tem conseguido alterar o modelo vigente, nem unificar as várias organizações de saúde ou viabilizar a integração sanitária.

É na gestão do cotidiano que os sujeitos individuais se transformam em sujeitos "autônomos ou sujeitados" (Campos, 1992b). O fazer da enfermeira neste cotidiano necessita de uma redefinição no modo de gerenciar, privilegiando ações democráticas e participativas de cunho promocional e preventivo, de tal maneira que a mudança deste fazer implique na possibilidade de transformação de um sujeito "sujeitado" para um sujeito "autônomo". Isto dependerá de uma reestruturação de todo um sistema conceitual, na medida em que o trabalho da equipe de saúde (especificamente da enfermeira) decorre das 
relações que esta estabelece com as diferentes instâncias que integram a estrutura social.

Enfim, este trabalho tem como pretensão iniciar uma discussão....

ABSTRACT: This survey consists of a theoretical reflection on the nurse's doing-abouts in the Local Health System (SILOS), allowing the understanding (though temporary) wheter the space she occupies at the "entrance door" of the health services has allowed the ideologic construction of her social action, as an individual or collective subject. Thus, we have sought theoretical guidance in the thoughts of Testa (1995) and pointed the SILOS as a social space of the Health System transformation. We have also discussed the relations experienced in the daily life of the institutional organization, trying to understand the production process of social subjects, focusing the nurse and this construction.

KEYWORDS: Local health system - Individual and collective actor - Health practices.

\section{REFERÊNCIAS BIBLIOGRÁFICAS}

1. ALMEIDA, M. C. P.de. O Trabalho de Enfermagem e sua articulação com o processo de trabalho em Saúde Coletiva - Rede Básica de Saúde em Ribeirão Preto. Ribeirão Preto, 1991. 297p. Tese (Livre Docência) apresentada na Escola de Enfermagem de Ribeirão Preto da Universidade de São Paulo.

2. ASSIS, M. M. A. A Municipalização da Saúde em Feira de Santana-Ba: Intenção ou Realidade? Ribeirão Preto, 1994. 210p. Dissertação e Mestrado apresentada na Escola de Enfermagem de Ribeirão Preto da Universidade de São Paulo.

3. BODSTEIN, R. (Org.). Serviços Locais de Saúde: Construção de Atores e Políticas. Rio de Janeiro: Relumé/Dumará, 1993.

4. Brasil, Constituição da República Federativa do Brasil. Edição da Assembléia Legislativa do Estado do Rio Grande do Sul, 1988.

5. CAMPOS, G. W. S. A Saúde Pública e a Defesa da Vida. São Paulo: HUCITEC, 1991.

6. Reforma da Reforma. Repensando a Saúde. São Paulo: HUCITEC, 1992. 
7 Sobre a peleja dos sujeitos da reforma, ou da reforma dos sujeitos em peleja. Saúde e Sociedade. v.1, n.2, p.79-96, 1992b.

8. CASTORIADIS, C. O Estado do Sujeito Hoje. IN: O Mundo FragmentadoEncruzilhadas do Labirinto III. Rio de Janeiro: Paz e Terra, 1992.

9. DRAIBE, S.M. As Politicas Sociais e o Neoliberalismo. Revista USP. Dossiê Liberalismo/Neoliberalismo. n.17, p.86-101, 1993.

10. FOUCAULT, M. Microfísica do poder. 6 ed, Rio de Janeiro: Graal, 1986.

11. GRAMSCI, A. Concepção Dialética da História. 9 ed, Rio de Janeiro: Civilização Brasileira, 1991.

12. KADT, E. de e TASCA, R. Promovendo a eqüidade um novo enfoque com base no setor saúde. São Paulo/Salvador: HUCITEC/Cooperação Italiana em Saúde, 1993.

13. MENDES, E.V. (Org.). Distrito Sanitário - O processo social de mudanças das práticas sanitárias do Sistema Único de Saúde. 2 ed. São Paulo/Rio de Janeiro: HUCITEC/ABRASCO, 1994.

14. MERHY, E.E. A luta na saúde pela defesa da vida e algumas questões sobre o seu sujeito formulador: contribuições para o planejamento e a gestão dos serviços. Campinas: UNICAMP, 1992 (Mimeografado)

15. MINISTÉRIO DA SAÚDE. $8^{a}$ Conferência Nacional de Saúde,Brasilia 17 a 21 de março de 1986, ANAIS... Brasilia, Centro de Documentação da Saúde, 1986.

16. TARIMO,E.; FOWKES, F.G.R. Sistemas distritales de Salud. Como reforzar la colluna vertebral de la atención primaria de salud. Foro Mundial de la Salud. v.10, n.1, p.76-81, 1989.

17. TEIXEIRA, C. F.; MELO, C. (Org..). Construindo Distritos Sanitários. A Experiência da Cooperação Italiana no Municipio de São Paulo. São Paulo/Salvador: HUCITEC/Cooperação Italiana em Saúde, 1995.

18. TESTA, M. Pensamento Estratégico e Lógica de Programação. O Caso da Saúde. São Paulo/Rio de Janeiro: HUCITEC/ABRASCO, 1995. 